\title{
The routine use of LCD-Array hybridisation technique for HPV subtyping in the diagnosis of penile carcinoma compared to other methods
}

Ria Winkelmann ${ }^{1 *}\left(\mathbb{D}\right.$, Katrin Bankov ${ }^{1}$, Jens von der Grün ${ }^{2}$, Jindrich Cinatl Jr. ${ }^{3}$, Peter J. Wild ${ }^{1}$, Stefan Vallo ${ }^{3 \dagger}$ and Melanie Demes ${ }^{1 \dagger}$

\begin{abstract}
Background: Routine human papillomavirus (HPV) testing is performed in cervival cancer and is required for classification of some head and neck cancers. In penile cancer a statement on HPV association of the carcinoma is required. In most cases p16 immunohistochemistry as a surrogate marker is applied in this setting. Since differing clinical outcomes for HPV positive and HPV negative tumors are described we await HPV testing to be requested more frequently by clinicians, also in the context of HPV vaccination, where other HPV subtypes are expected to emerge.
\end{abstract}

Method: Therefore, a cohort of archived, formalin-fixed paraffin embedded (FFPE) penile neoplasias was stained for p16 and thereafter tested for HPV infection status via PCR based methods. Additionally to Sanger sequencing, we chose LCD-Array technique (HPV 3.5 LCD-Array Kit, Chipron; LCD-Array) for the detection of HPV in our probes expecting a less time consuming and sensitive HPV test for our probes.

Results: We found that LCD-Array is a sensitive and feasible method for HPV testing in routine diagnostics applicable to FFPE material in our cohort. Our cohort of penile carcinomas and carcinomas in situ was associated with HPV infection in $61 \%$ of cases. We detected no significant association between HPV infection status and histomorphological tumor characteristics as well as overall survival.

Conclusions: We showed usability of molecular HPV testing on a cohort of archived penile carcinomas. To the best of our knowledge, this is the first study investigating LCD-Array technique on a cohort of penile neoplasias.

Keywords: Urological oncology, Viral infection, Viral oncology, Screening, HPV infection, Penile carcinomas, Sanger Sequencing, p16, LCD-Array

\footnotetext{
*Correspondence: ria.winkelmann@kgu.de

${ }^{\dagger}$ Stefan Vallo and Melanie Demes should be considered joint senior author

${ }^{1}$ Dr. Senckenberg Institute of Pathology, University of Frankfurt,

Theodor-Stern-Kai 7, 60596 Frankfurt am Main, Germany

Full list of author information is available at the end of the article
}

\begin{abstract}
Background
Infection by human papillomavirus (HPV) is associated with a variety of cancers including anal squamous cell carcinomas (SCC), oropharyngeal cancers, cervical cancers, vulvar and vaginal cancers as well as penile carcinomas [1]. Penile neoplasia is a rare disease entity in Europe and the USA with an incidence of less than $1 / 100.000$ [2]. The WHO classification of diseases describes HPV-related and non-HPV-related penile
\end{abstract}


squamous cell carcinomas [3]. HPV infection rates in penile cancers vary from study to study from about one third to two thirds [4]. Penile carcinomas not related to HPV are thought to be associated with numerous factors, for example lack of neonatal circumcision and cigarette smoking [5]. The current S3 guideline for penile carcinomas states that it is necessary to give a statement on HPV association of the carcinoma [6]. The outcome of HPV-associated cancers, such as anal squamous cell carcinomas and oropharyngeal carcinomas, as well as penile carcinomas differ from non-HPV-related cancers [7, 8]. In routine diagnostics an antibody against p16 is recommended for the detection of HPV infections in penile carcinomas [9]. p16 serves as a surrogate marker to detect a possible infection by HPV. Stainings are mostly positive in case of infection by high risk HPV subtypes. Interpreting the staining result needs some experience to not over interpret weak or mosaic-like staining patterns as clearcut positive results. In uncertain cases, another method that can be applied on formalin fixed paraffin embedded (FFPE) tissue specimen is needed. Additionally, due to differences in clinical outcomes for HPV positive and HPV negative tumors reliable HPV testing may become requested more frequently by clinicians, also in the context of HPV vaccination, where other HPV subtypes are expected to emerge.

We used p16 immunohistochemistry, Sanger sequencing and the LCD-Array hybridisation technique (Chipron) for HPV detection on a cohort of penile squamous cell carcinomas, carcinomas in situ and peritumoral tissue and compared the sensitivity and specificity, respectively. We chose LCD-Array hybridisation technique (Chipron) in direct comparison to Sanger sequencing expecting reduced hands-on time and easy interpretation of the results. To shed light on the question of which test is the most efficient one for daily routine, we compared the above mentioned three distinct tests. To our knowledge, this is the first study testing LCD array technique on a cohort of FFPE material of penile neoplasias.

\section{Methods}

\section{Patient characteristics}

Between 2002 and 201770 cases with sufficient FFPE material were identified with penile squamous cell carcinomas, squamous cell carcinoma in situ (Cais) of the penis, extramammary Paget disease, focally invasive as well as basal cell carcinoma of the penis. The paraffin blocks were provided by the Dr. Senckenberg Institute of Pathology, University Hospital, Frankfurt, Germany.

We systematically compared tumor and individual matching non-tumor probes for 69 of 70 cases. In a single case, a lymph node metastasis was investigated.
Therefore, we applied a total of 139 tests, for one probe only metastatic material was available. In total, we investigated 62 invasive squamous cell carcinomas, 6 squamous cell carcinomas in situ, one basal cell carcinoma, and one extramammary Paget disease, focally invasive. Additionally, peritumoral epithelium was tested, wherever available. The peritumoral epithelium was macrodissected or taken from another block wherever available.

Median age at diagnosis was 65 years (range $41-85$ years). The lesions were mostly located at the glans penis $(n=50)$, followed by the foreskin $(n=9)$ and shaft $(\mathrm{n}=2)$. In 9 cases, the primary tumor localisation could not be determined due to either a large tumor size or incomplete documentation.

Penile carcinomas were staged and characterized according to TNM staging and the 8th edition of the classification system of the Union for International Cancer Control (UICC) [9]. The tumor classification is displayed in Table 1. Tumor size and infiltration depth were recorded for all tumors. In cases of incomplete excision,

Table 1 Characteristics of invasive squamous cell carcinomas of the penis $\left(n=60^{*}\right)$

\begin{tabular}{|c|c|c|}
\hline Characteristics & $\mathbf{n}$ & $\%^{* *}$ \\
\hline pTX & 2 & 3 \\
\hline pT1a & 23 & 38 \\
\hline pT1b & 7 & 12 \\
\hline pT2 & 23 & 38 \\
\hline pT3 & 3 & 5 \\
\hline pT4 & 2 & 3 \\
\hline pNX & 38 & 63 \\
\hline pNO & 13 & 22 \\
\hline pN1, pN2, pN3 & 9 & 15 \\
\hline LX & 1 & 2 \\
\hline LO & 47 & 78 \\
\hline L1 & 12 & 20 \\
\hline$V x$ & 1 & 2 \\
\hline V0 & 54 & 90 \\
\hline V1 & 5 & 8 \\
\hline $\operatorname{Pn} X$ & 1 & 2 \\
\hline Pno & 53 & 88 \\
\hline Pn1 & 6 & 10 \\
\hline G1 & 12 & 20 \\
\hline G2 & 39 & 65 \\
\hline G3 & 9 & 15 \\
\hline Usual morphology & 54 & 90 \\
\hline Basaloid morphology & 6 & 10 \\
\hline Infiltrative pattern & 38 & 63 \\
\hline Pushing borders & 22 & 37 \\
\hline
\end{tabular}

*In two cases only central biopsy probe or metastasis was present

**\% may not add up to 100 because of rounding 
or undeterminable tumor size, the tumor measurements were not included. Infiltration depth was measured in $\mathrm{mm}$ from deepest infiltration to epithelium for all tumors.

Tissue samples and patient data used in this study were provided by the University Cancer Center Frankfurt (UCT). Written informed consent was obtained from all patients and the study was approved by the institutional review board of the UCT and the ethical committee at the University Hospital Frankfurt (project-number: SUG02-2017) according to the declaration of Helsinki. For our studies, archived material was used in a double pseudonymised manner. Diagnostics were already finalised by the time of study.

\section{p16 staining}

All cases were stained with an antibody against p16. Briefly, freshly cut $1 \mu \mathrm{m}$ thick paraffin sections were stained using CINtec $^{\circledR}$ (Roche, Basel, Switzerland) according to manufacturers' instructions. Immunohistochemistry was performed using the DAKO FLEXEnvision Kit (Agilent, Santa Clara, CA, US) and the fully automated DAKO Omnis staining system (Agilent, Santa Clara, CA, US) according to manufacturer's instructions. Epitope retrieval was generated at $\mathrm{pH} 6$ and $97{ }^{\circ} \mathrm{C}$. Epitope staining was applied for $30 \mathrm{~min}$. Epitope visualization was done by DAKO EnVision ${ }^{\text {TM }}$ FLEX DAB + Substrate Chromogen System (Agilent, Santa Clara, CA, US). DAKO haematoxylin solution (Agilent, Santa Clara, CA, US) was used for nuclear counterstaining. Positive staining was noted in the case of block like positive staining. Mosaic staining pattern was noted as negative.

\section{DNA extraction}

Tumor and non-tumor samples were macrodissected from $10 \mu \mathrm{m}$ thick paraffin sections that were freshly cut. DNA extraction was performed applying the Maxwell 16 FFPE tissue LEV DNA purification kit (Promega, Madison, WI, USA). Quantification was performed using Quantus Fluorometer (Promega, Madison, WI). DNA quality was assessed by fragment analysis (ABI Genetic Analyzer, Thermo Fisher). HPV subtypes were analysed by Sanger sequencing and compared to LCD-Array technique (Chipron, Berlin, Germany).

\section{Sanger sequencing}

Nested polymerase chain reaction (PCR) using GP5+/6+ and MY09/11 primers, commonly used for HPV detection, were tested on a subset of probes as described previously [10]. Primer sequences were: $\left(5^{\prime}-3^{\prime}\right)$ MY9: CGTCCMARRGGAWACTGATC, MY 11 GCMCAG GGWCTATAAYAATGG, GP5 + TTTGTTACTGTG GTAGATACYAC, and GP6+GAAAAATAAACTGTA
AATCATATTC [10]. After PCR, a gel was run to test for products and correct sizes. In case a product was shown, it was subject to Sanger sequencing with My09/11 primers as described [10] on 3130xl Genetic Analyzer (ThermoFisher Scientific, Darmstadt, Germany) running the 3130 Series Data Collection Software v.3.0. PCR settings were the following: $95{ }^{\circ} \mathrm{C}$ for $2 \mathrm{~min}$, and 39 times $95{ }^{\circ} \mathrm{C}$ for $1 \mathrm{~min}, 60^{\circ} \mathrm{C}$ for $1 \mathrm{~min}$ and $72^{\circ} \mathrm{C}$ for $1 \mathrm{~min}$ followed by $72{ }^{\circ} \mathrm{C}$ for $10 \mathrm{~min}$. Termination was at $15^{\circ} \mathrm{C}$. Some probes were sent to Eurofins Genomics, Ebersberg, Germany for sequencing. The sequence of the forward and reverse reaction were subject to a Basic local Alignment Search Tool (BLAST) search [11]. One positive control containing HPV 16 was run with each sequencing test. Results were subject to evaluation via BLAST search in case of evaluable sequencing reults for forward and reverse primer. In case only one primer resulted in a sequence result it was declared negative.

\section{HPV testing with LCD-Array kit}

All samples were re-analysed by applying HPV 3.5 LCDArray Kit (LCD-Array, Chipron, Berlin, Germany), according to manufacturers' instructions (https://www. chipron.com). PCR settings were the following: Start at $96{ }^{\circ} \mathrm{C}$ for $3 \mathrm{~min}, 42$ times $94{ }^{\circ} \mathrm{C}$ for $1 \mathrm{~min}, 45^{\circ} \mathrm{C}$ for $1 \mathrm{~min}$ and $30 \mathrm{~s}, 72{ }^{\circ} \mathrm{C}$ for $1 \mathrm{~min}$ and $30 \mathrm{~s}$, finalized by $72{ }^{\circ} \mathrm{C}$ for 3 min and termination at $4{ }^{\circ} \mathrm{C}$. The following HPV subtypes can be detected: $6,11,16,18,31,33,35,39,42,44$, $45,51,52,53,54,56,58,59,61,62,66,67,68,70,72,73$, $81,82,83,84,90$ and 91 . Tumor and non-tumor samples were tested in pairs. One positive and one negative control were taken per run. Figure 1 summarises the workflow and displays results.

\section{Data analysis}

Data was tested for normal distribution and subject to tests according to their distribution using $\mathrm{BiAS}^{\mathrm{TM}}$ [12]. Distribution was tested using the Kolmogorov-Smirnov test. Further methods used were Spearman's rank correlation as well as Fisher's exact test and contingency tables for sensitivity and specificity and Cohen's $d$ for calculation of effect strength and student's t-test. Additionally Kaplan-Meier-estimator and Log-rank-test, Cox-Mantel and Peto-Pike were applied. Due to multiple testing, Bonferroni correction was applied.

\section{Results}

\section{Tumor characteristics and growth pattern}

The cohort of 70 penile neoplasias (62 invasive squamous cell carcinomas, 6 carcinomas in situ, one case of basal cell carcinoma, one case of extramammary Paget disease, focally invasive) was investigated. Two samples inherited either metastasis or central biopsy probe. All tumor and 


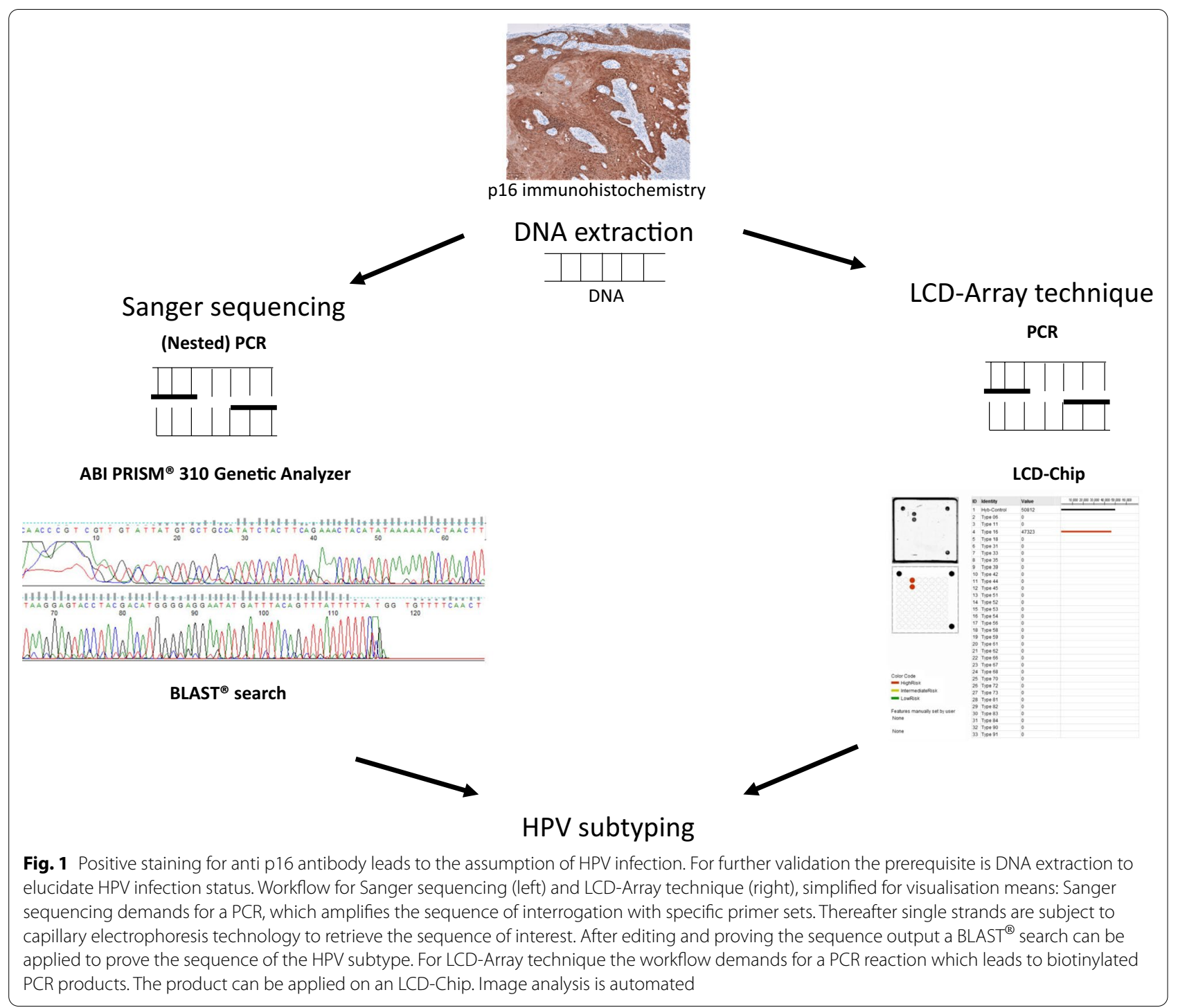

non-tumor specimens were screened, wherever applicable, for p16 and HPV status (in total 139 probes, since in one case only a metastasis could be evaluated).

Most of the invasive squamous cell carcinomas were stage pT1a and pT2. Six cases displayed Carcinoma in situ $(6 / 70,9 \%)$ and two cases $(2 / 70,3 \%)$ consisted of extramammary Paget disease, focally invasive and basal cell carcinoma.

In our cohort we detected exceedingly more squamous cell carcinomas, usual type $(54 / 60,90 \%)$, then squamous cell carcinomas, basaloid type $(6 / 60,10 \%)$. In many cases lymph nodes were not removed (pNX; 38/60, 63\%). Most cases displayed no (lympho-)vascular invasion (L0, 47/60, $78 \%, \mathrm{~V} 0,54 / 60,90 \%)$ and no perineural invasion (Pn0, $53 / 60,88 \%)$. In most cases tumor grading was determined as G2 (39/60, 65\%) on a scale G1-G3 (see Table 1 for a summary of tumor characteristics).

\section{P16 immunohistochemistry}

In 70 samples we tested tumor and non-tumor for HPV and p16 status. One probe harboured only metastasis. In one sample p16 staining of non-tumor material could not be evaluated due to technical reasons (therefore $\mathrm{n}=138$ ). In total block like p16 positivity was detected in 39/138 (28\%) evaluable samples.

Invasive SCCs $(\mathrm{n}=62)$ were $\mathrm{p} 16$ positive in 32 cases (32/62, 52\%). Carcinoma in situ were positive in $4 / 6$ cases (67\%). Extramammary Paget disease, focally invasive and basal cell carcinoma resulted negative for $\mathrm{p} 16$ staining.

For non-neoplastic epithelium 68 (68/69, 99\%) cases were evaluable. Peritumoral epithelium was positive for p16 immunohistochemistry in 3 cases $(3 / 68,4 \%)$. All stainings are displayed in Additional file 1: Fig. 1 and Additional file 2: Fig. 2. 


\section{Sanger sequencing}

Overall, 137 samples consisting of tumor and non-tumor probes could be evaluated (137/139, 99\%) by Sanger sequencing. HPV infection was detected in 21 samples $(21 / 137,15 \%)$.

61 of 62 (98\%) invasive squamous cell carcinomas were evaluable via Sanger sequencing. 16/61 (26\%) invasive carcinomas were positive for HPV infection: 13 cases showed positivity for HPV 16 (13/61, 21\%). The remaining 3 cases harboured 2 co-infections HPV 16 and 33 $(2 / 61,3 \%)$ and one HPV 33 infection $(1 / 61,2 \%)$.

For carcinoma in situ $(n=6)$ all cases were evaluable $(6 / 6,100 \%) .1$ case showed HPV infection $(1 / 6,17 \%)$ with HPV 16. The remaining 5 cases were negative for HPV infection (5/6, 83\%).

Extramammary Paget disease, focally invasive and basal cell carcinoma were negative for HPV infection by Sanger sequencing.

Matching non-neoplastic epithelium was evaluable in 68/69 (99\%) cases. 4/68 (6\%) cases harboured HPV infection by HPV 16.

\section{HPV status via LCD-Array}

In total 134/139 (96\%) samples showed sufficient material for LCD-Array analysis. Of these HPV infection was detected in 58 probes $(58 / 134,43 \%)$.

With LCD-Array technique, 60/62 (97\%) invasive carcinomas were evaluable. $34 / 60(57 \%)$ probes tested were positive for HPV infection. Among these, HPV 16 was the most frequent: 26/60 (43\%). Eight remaining cases harboured infections by HPV $11(2 / 60,3 \%)$, HPV 31 (1/60, 2\%), HPV $33(1 / 60,2 \%)$ and 4 cases showed coinfections of HPV 16 and 44, HPV 16 and 58, HPV 16 and 70 as well as HPV 18 and 53 (4/60,7\%). The results are summarised in Fig. 2.

Carcinoma in situ $(\mathrm{n}=6)$ were tested positive for HPV infection in $100 \%$ of cases (6/6). $5 / 6$ (83\%) showed HPV 16 mono-infection. One case showed co-infection with HPV 16 and 33 (1/6, 17\%).

Extramammary Paget disease, focally invasive and Basal cell carcinoma were both negative for HPV infection via LCD-Array technique.

For non-neoplastic epithelium, 66/69 (96\%) were evaluable. 18/66 (27\%) showed infection by HPV: HPV 16 was proven in $16 / 66$ (24\%) of cases. The remaining two cases harboured an infection by HPV 11 and a co-infection of HPV 16 and 33 (each 1/66, 2\%).

Results for p16, Sanger sequencing and LCD-Array technique are summarised in Table 2.

\section{Quality assurance (reference pathological assessment)}

Five cases with positive results in peritumoral epithelium via LCD-Array technique were additionally investigated at another lab (https://www.aid-diagnostika.com/) by strip hybridization (AID Diagnostica) with 100\% concordance.

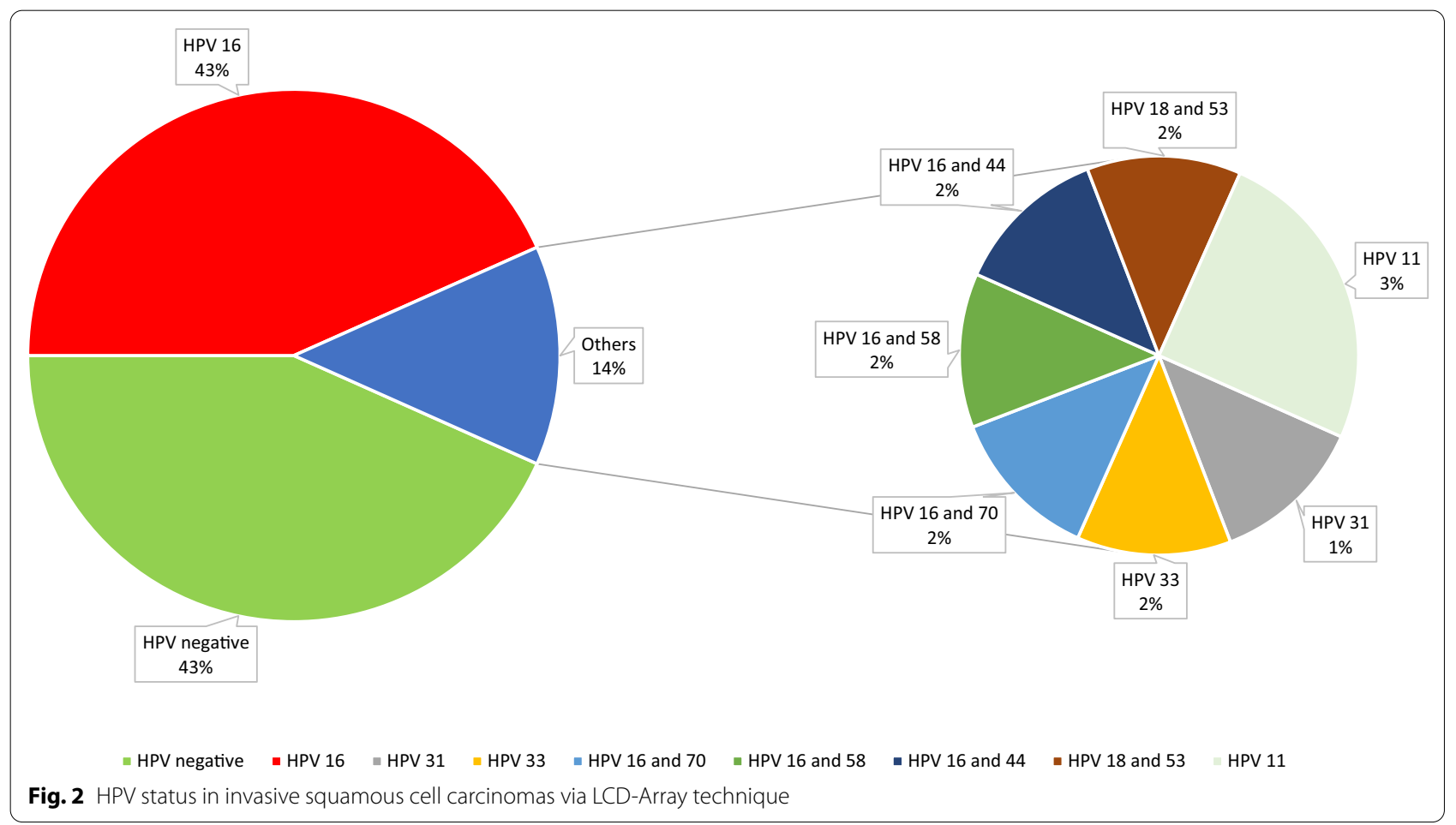


Table 2 Results for p16 staining, Sanger sequencing and LCD-Array technique for squamous cell carcinomas, carcinoma in situ (Cais) and non-tumor tissue as well as overall

\begin{tabular}{|c|c|c|c|c|c|c|}
\hline \multirow[t]{2}{*}{ Sample } & \multicolumn{2}{|l|}{ p16 } & \multicolumn{2}{|c|}{ Sanger sequencing } & \multicolumn{2}{|c|}{ LCD-Array technique } \\
\hline & positive (\%) & negative (\%) & positive (\%) & negative (\%) & positive (\%) & negative (\%) \\
\hline Squamous cell carcinomas $(n=62)$ & $32 / 62(52 \%)$ & $30 / 62(48 \%)$ & $16 / 61(26 \%)$ & $45 / 61(74 \%)$ & $34 / 60(57 \%)$ & 26/60 (43\%) \\
\hline Cais $(n=6)$ & $4 / 6(67 \%)$ & $2 / 6(33 \%)$ & $1 / 6(17 \%)$ & $5 / 6(83 \%)$ & $6 / 6(100 \%)$ & $0(0 \%)$ \\
\hline non-tumor tissue $(n=69)$ & $3 / 68(4 \%)$ & 65/68 (96\%) & $4 / 68(6 \%)$ & $64 / 68$ (94\%) & 18/66 (27\%) & $48 / 66(73 \%)$ \\
\hline Overall $(n=139)$ & $39 / 138(28 \%)$ & 99/138 (72\%) & $21 / 137(15 \%)$ & $116 / 137(85 \%)$ & $58 / 134(43 \%)$ & 76/134 (57\%) \\
\hline
\end{tabular}

Extramammary Paget disease, focally invasive and basal cell carcinoma were negative for p16 staining, and showed no HPV infection via Sanger sequencing and LCDArray technique

LCD-Array technique detects HPV infection status directly in comparison to p16 testing and results in testing of multiple viruses in one sample. Therefore, we chose LCD-Array data as a gold standard for our statistical analysis. HPV status was based on LCD-Array data.

\section{Sensitivity and specificity}

LCD-Array technique was taken as gold standard. For a direct comparison of all three techniques (Fig. 3, [13]) results were simplified as positive, negative and not evaluable. For p16, a positive block-like staining result was taken as positive and for sequencing techniques an evaluable measurement was taken as a result. For $n=131$ samples data for all three techniques (p16, Sanger sequencing and LCD-Array technique) were applicable. Two cases revealed HPV 11 (low risk) and therefore negative p16 staining. These two cases were also not considered in direct comparison of all three techniques $(n=129)$.

The total overlap between all three techniques was 87 samples of 129 (67\%). Overlap means that a positive p16 staining results in a HPV subtype determination via Sanger sequencing and LCD-Array and vice versa:

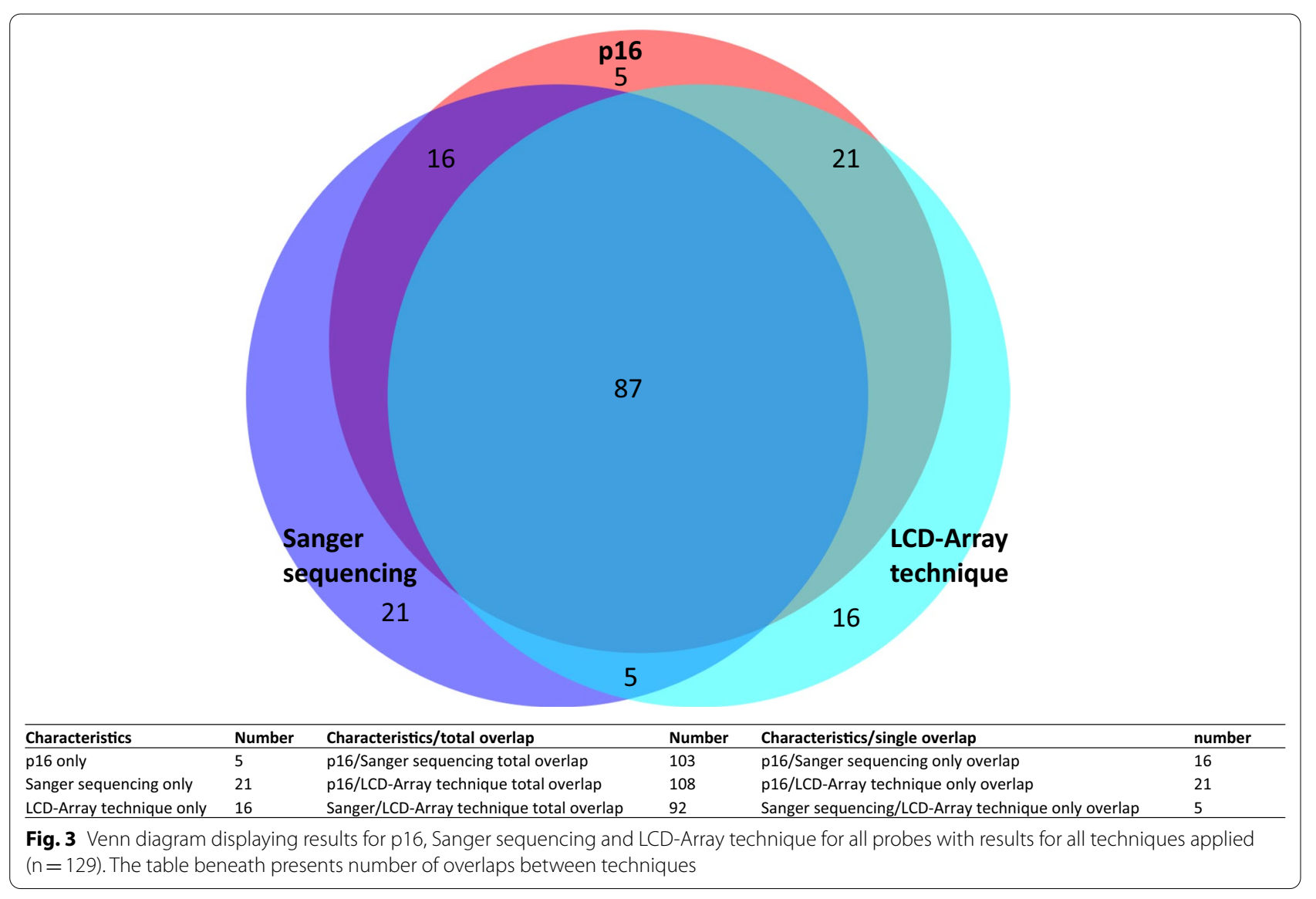


negative p16 staining should lead to negative HPV proof by the other techniques.

The overlap between p16 and Sanger sequencing was $103 / 129$ (80\%) cases, the overlap between p16 and LCDArray technique was 108/129 (84\%) cases, and between Sanger sequencing and LCD-Array technique was 92/129 (71\%) cases.

LCD-Array technique taken as gold standard lead to a sensitivity of $63 \%$ and a specificity of $100 \%$ for p16 staining, respectively. Prevalence was $43 \%$. The rate of false positives was $0 \%$, the rate of false negatives was $38 \%$. Positive predictive value was $100 \%$, negative predictive value was $78 \%$.

Taking LCD-Array technique as gold standard Sanger sequencing had a sensitivity of $34 \%$ and a specificity of $100 \%$. Prevalence was $43 \%$. The rate of false positives was $0 \%$, the rate of false negatives was $66 \%$. Positive predictive value was $100 \%$ and the negative predictive value was $66 \%$.

\section{Squamous cell carcinomas}

For squamous cell carcinomas $n=57$ samples contained measurements for all three techniques. The total overlap between all three techniques in squamous cell carcinomas was 39 (39/57, 68\%).

Concordant and discrepant results in squamous cell carcinomas are displayed in Fig. 4. Sanger sequencing and LCD-Array technique showed overlapping negative results. For p16 staining 3 stains were negative but HPV 16 was shown via LCD-Array technique.
Looking at squamous cell carcinomas per se and taking LCD-Array as the gold standard, the prevalence for p16 positivity was $56 \%$, sensitivity was $91 \%$, specificity was $100 \%$. The rate of false positives was $0 \%$, the rate of false negatives was $9 \%$. The positive predictive value of p16 staining was $100 \%$ and the negative predictive value was $89 \%$.

Comparing Sanger sequencing and LCD-Array technique, taking LCD-Array technique as the gold standard, prevalence was $56 \%$, sensitivity was $47 \%$, specificity was $100 \%$. The rate of false positives was $0 \%$ and rate of false negatives was $53 \%$. The positive predictive value was $100 \%$ and the negative predictive value was $60 \%$.

\section{HPV status via LCD-Array technique with regard to tumor characteristics and survival}

HPV status was related to tumor characteristics. Fisher's exact test showed a tendency towards an association between HPV status and tumor stage for LCD-Array technique $(p=0.027$; Table 3; not significant after Bonferroni correction). Carcinoma in situ showed HPV infection in $100 \%$ of the cases $(6 / 6)$ with six of six cases revealing HPV 16 infection and one of these cases with a co-infection 16 and 33. No HPV infection was detected in the basal cell cancer $(0 / 1)$ and extramammary Paget disease, focally invasive $(0 / 1)$. Bonferroni correction of p-values based on multiple tests showed no significant association between HPV status and tumor characteristics (Table 3). For comparison, the results are also displayed in relation to HPV status via p16 immunohistochemistry and Sanger sequencing in Additional file 4:

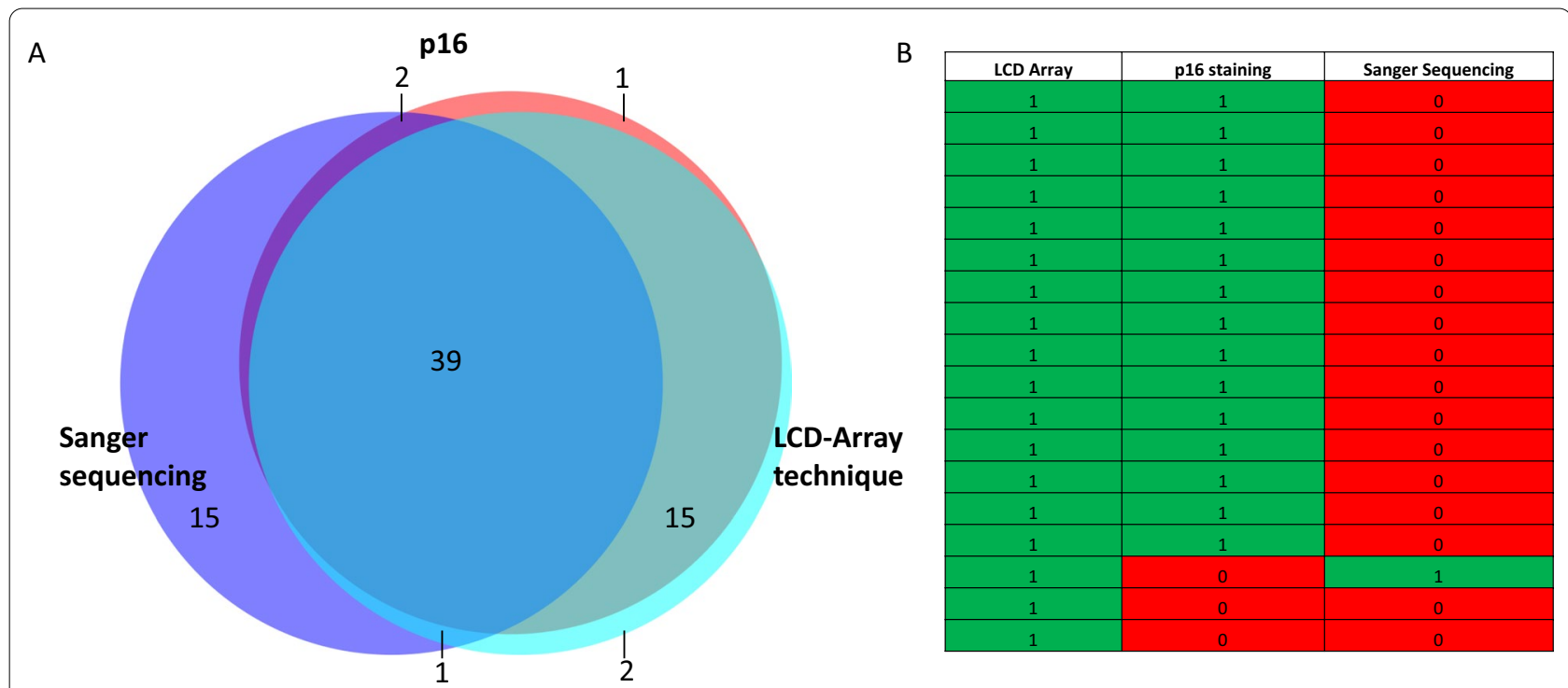

Fig. 4 A Venn diagram displaying overlaps and controversies of p16, Sanger sequencing and LCD-Array technique in invasive squamous cell carcinomas of the penis. B Detailed report of the mismatches between all p16, Sanger sequencing and LCD-Array technique 
Table 3 HPV status by LCD-Array technique with regard to tumor characteristics in evalulable cases

\begin{tabular}{|c|c|c|c|}
\hline Characteristics & $\begin{array}{l}\text { HPV high risk } \\
\text { negative (n) }\end{array}$ & $\begin{array}{l}\text { HPV high risk } \\
\text { positive (n) }\end{array}$ & $p^{* * *}$ \\
\hline pTX & 2 & 0 & 0.027 \\
\hline pT1a & 8 & 14 & \\
\hline pT1b & 2 & 5 & \\
\hline pT2 & 15 & 7 & \\
\hline pT3 & 0 & 3 & \\
\hline pT4 & 0 & 2 & \\
\hline pNX & 14 & 22 & 0.336 \\
\hline pNO & 8 & 5 & \\
\hline pN1, pN2, pN3 & 5 & 4 & \\
\hline LX & 1 & 0 & 0.743 \\
\hline LO & 21 & 24 & \\
\hline L1 & 5 & 7 & \\
\hline$V X$ & 1 & 0 & 0.493 \\
\hline Vo & 23 & 29 & \\
\hline V1 & 3 & 2 & \\
\hline $\operatorname{PnX}$ & 1 & 0 & 0.393 \\
\hline PnO & 22 & 29 & \\
\hline Pn1 & 4 & 2 & \\
\hline G1 & 9 & 3 & 0.087 \\
\hline G2 & 14 & 23 & \\
\hline G3 & 4 & 5 & \\
\hline usual morphology & 25 & 27 & 0.675 \\
\hline basaloid morphology & 2 & 4 & \\
\hline infiltrative pattern & 16 & 20 & 0.788 \\
\hline pushing borders & 11 & 11 & \\
\hline
\end{tabular}

***Fisher-Freeman-Halton's exact contingency table-test. Bonferroni correction resulted in non-significant $p$-values

Table 1a and 1b: For p16 status a statistical significant association between nodal stage $(\mathrm{p}=0.04)$ and grading $(p=0.023)$ was shown. For Sanger sequencing a statistical significant association was shown regarding nodal stage $(\mathrm{p}=0.01)$. The $\mathrm{p}$-values displayed are not significant after Bonferroni correction. There was no significant difference regarding overall survival in this cohort with all three techniques as displayed in Additional file 3: Fig. 3.

\section{Tumor size and infiltration depth}

The mean tumor size was $30 \mathrm{~mm}$ overall (median: $22 \mathrm{~mm}$; range $4-140 \mathrm{~mm} ; \mathrm{n}=49$ evaluable samples). The mean infiltration depth was $6 \mathrm{~mm}$ (median: $5 \mathrm{~mm}$; range 1-24 mm; $n=49$ evaluable samples). There was no significant association between tumor size and infiltration depth in relation to HPV status obtained via LCD-Array technique (Table 4).

\section{Discussion}

To establish the LCD-Array hybridisation technique in routine diagnostics for the HPV analysis of penile carcinomas, we examined penile carcinomas, penile carcinomas in situ und peritumoral epithelium expecting a variable rate of $\mathrm{HPV}$ infections.

As a surrogate for possible HPV infection in routine diagnostics, p16 immunohistochemistry is widely applied, for example in oropharyngeal carcinomas, where a positive staining will serve as a marker for clinical behaviour of the tumor [14]. In our cohort of invasive squamous cell carcinomas we found three cases without p16 staining but with a positive HPV test, when applying the LCD-Array technique. Varying expression patterns of p16 may be derived from certain reasons: Negative or partially positive p16 staining can, in case of infection, be explained by gene methylation, loss of the protein in tumor cells due to genetic instability or low risk HPV infection [15]. Therefore, molecular techniques can shed light on an increasing number of patients that would have been missed in cases of negative p16 staining and can be applied as additional techniques.

Sanger sequencing with established primers was performed on archived formalin fixed paraffin embedded material in a lab routinely using Sanger sequencing

Table 4 Influence of HPV status detected via LCD-Array on tumor size and infiltration depth

\begin{tabular}{lllllll}
\hline Tumor size & \multicolumn{2}{l}{ Infiltration depth } & & \\
\cline { 2 - 6 } & HPV neg & HPV pos & $\begin{array}{l}\text { Cohen's effect size d with pooled } \\
\text { standard deviation**** }\end{array}$ & HPV neg & HPV positive & $\begin{array}{l}\text { Cohen's effect size d } \\
\text { with pooled standard } \\
\text { deviation }\end{array}$ \\
\hline N & 20 & 29 & 0.27 & 23 & 26 & 0.11 \\
Mean (mm) & 26 & 32 & (Welch's t-test: $t=1.01(p=0.32))$ & 7 & 6 \\
Median (mm) & 23 & 22 & & 5 & 5 \\
STD DEV & 18 & 29 & & 6 & 5 \\
Min (mm) & 7 & 4 & & 1 & 1 \\
Max (mm) & 85 & 140 & & 24 & 17 \\
\hline
\end{tabular}


method. Sanger sequencing is a technique, which is well established and is called the "gold-standard" for the validation of newly developed sequencing methods, also in HPV testing [16].

The advantage of Sanger sequencing is the interrogation of a longer segment, whereas LCD-Array technique is limited to certain subtypes of HPV.

Technically, hands on time differs between Sanger sequencing and LCD-Array: The LCD-Array Chip can be finished within one working day, whereas Sanger sequencing takes approximately two working days. DNA input and costs do not differ significantly.

The evaluation of results is more time consuming via Sanger sequencing technique since the LCD-Array hybridisation method has a visual feedback mechanism. Data interpretation of Sanger sequencing results demands experience and is partly subjective. Figure 1 gives an example for a positive p16 staining, Sanger sequencing and LCD-Array result. Limit of detection varies depending on the mutation investigated [17]. Discrepancies between Sanger sequencing and LCD-Array hybridisation technique can partly be attributed to differing sensitivities and specificities: For HPV it is known that the viral load can vary and is not necessarily related to cancer development $[18,19]$. Detection of co-infections via Sanger sequencing was inferior to LCD-Array technique, which is in line with a past study [16].

In our study, we applied FFPE material for HPV detection. FFPE material is a widely available material in pathologies. Due to fixation artefacts and storage time DNA yield can vary and can sometimes result in probe failure [20].

As of 2021 the Food and Drug Administration (FDA) approved several HPV testing methods: APTIMA HPV 16 18/45 Genotype Assay and APTIMA HPV Assay (Gen-Probe, Inc., San Diego, CA), Cervista HPV 16/18 and Cervista HPV HR and Genfind DNA Extraction Kit (Hologic, INC., Marlborough, MA), COBAS HPV Test and cobas HPV for use on the cobas 6800/8800 Systems (Roche Molecular Systems, Inc., Pleasanton, CA), Digene Hybrid Capture 2 High-Risk HPV DNA Test (QIAGEN GAITHERSBURG, INC, Germantown, MD) and BD ONCLARITY HPV ASSAY (BECTON, DICKINSON AND COMPANY, Sparks, MD) [21].

APTIMA HPV 16 18/45 Genotype Assay is indicated for the qualitative detection of E6/E7 viral messenger RNA (mRNA) of HPV types 16,18 and 45. It differentiates between HPV 16 and HPV 18 and/or HPV 45 [21]. APTIMA HPV ASSAY is an amplification test for the qualitative detection of E6/E7 (mRNA) to recognize HPV $16,18,31,33,35,39,45,51,52,56,58,59,66,68$. Discrimination of the HPV types is not intended [21]. Cervista HPV 16/18 qualitatively detects DNA from HPV type
16 and 18 by fluorescence signal [21]. Cervista HPV HR and Genfind DNA Extraction Kit is a qualitative test for the detection of 14 high risk HPV types $(16,18,31,33$, $35,39,45,51,52,56,58,59,66$, and 68 ) not discriminating the type [21]. COBAS HPV Test is PCR based and utilises nucleic acid hybridisation to detect 14 high risk HPV types, of which 16 and 18 are discriminated. The others include $31,33,35,39,45,51,52,56,58,59,66$ and 68 [21]. The digene HC2 High-Risk HPV DNA Test detects 13 high-risk HPV types, which are 16, 18, 31, 33, $35,39,45,51,52,56,58,59,68$ using full genome probes complementary to HPV DNA, specific antibodies, signal amplification, and chemiluminescent detection. It analyses HPV DNA high-risk groups [22]. BD Onclarity HPV Assay is PCR-based and uses nucleic acid hybridisation for the detection of 14 high risk HPV types discriminating 16, 18 and 45 and detecting 31, 33, 35, 39, 51, 52, 56, $58,59,66$ and 68 [21].

A study comparing sensitivity and specificity of the above mentioned tests showed that all DNA/RNA-based tests, except the NorChip test, showed high sensitivity rates for high-grade lesions positive by cytology [23]. These tests apply to non-FFPE material and test for limited subtypes of HPV, as described above.

The LCD-Array's performance was demonstrated by the HPV Laboratory Network (LabNet) in comparison to other tests with $100 \%$ proficient results [24]. The advantage of this test is its usability on FFPE material. Additionally, the aforementioned tests miss a certain amount of HPV infections. Those were all found by applying the LCD-Array technique in a recent study on gynaecological samples [25]. Studies comparing HPV genotyping methods described differences in HPV genotype detection depending on the technique used with concordance rates of minimum $77,6 \%$, declining when only looking at FFPE material [26-28]. Therefore, taking into account that archived FFPE material was used in this study the concordance rate seen here could also be attributed to DNA degradation.

The cohort of Frankfurt penile carcinomas and carcinomas in situ was associated with HPV infection in $61 \%$ (40/66 evaluable samples; 6 Carcinoma in situ, 34 invasive carcinomas) of the cases as defined by LCD-Array technique, which is in line with other studies [2,15] and higher than in a recent review [29]. Basal cell carcinoma was negative for HPV infection using PCR-based techniques and via p16 staining. Cases of p16 positive basal cell carcinomas were described in the literature [30]. Nevertheless, in our case, HPV subtyping for mucosal/ genital high risk viral infection of the HPV was negative. Most likely the HPV infection was not detected by our techniques because the specific beta-family of HPV subtypes, mostly associated with these tumors [31], was 
not interrogated by our assays. For extramammary Paget disease, p16 expression is also reported in the literature. There is variable attribution to HPV infection status [32].

We were able to show HPV infection in peritumoral epithelium (18/66, 27\%; see above). Positive measurement in non-neoplastic epithelium resulted in positive measurement in neoplastic epithelium. The question needs to be raised, why, despite HPV infection in both fractions, one resulted in tumor growth and the other did not. The HIM Trial postulates up to $37 \mathrm{HPV}$ types in the genitals, of which ca. $5 \%$ progressed to a genital lesion [33]. It can be speculated, whether this might be due to transient HPV infections, which can be cleared by the immune system [34]. Furthermore the observations need to be questioned concerning their clinical impact: The pure measurement of HPV infection via molecular techniques in non-neoplastic tissue may account for a sensitive technique but could raise concerns in the management of the patient. Negative p16 stainings in nonneoplastic epithelium in case of positive measurements by molecular techniques should therefore, formally not be regarded as false negatives. For this reasen molecular techniques should be used in addition to p16 stainings for uncertain cases or maybe in the setting of clinical trials.

As expected, the most frequent type of HPV infection in squamous cell carcinomas resulted from HPV 16. That is in line with previous studies [35].

In the tumor cohort, we investigated squamous cell carcinomas of the usual type and basaloid subtype. Although the usual type is classified as non-HPV-related, according to the WHO classification, we found 30 samples with HPV infections among 54 evaluable tumor samples described as squamous cell carcinoma, usual type (56\% positive samples), which is in line with a previous review [36]. We have found no significant association between HPV infection status and tumor characteristics according to TNM classification system as well as tumor size, overall survival and infiltration depth in our cohort. Differing prognosis for HPV positive and HPV negative cases have been reported in other cancer types, such as head and neck cancer [37]. Moreover, in our cohort a significant association between overall survival depending on the technique for HPV detection applied was not shown. Maybe this can partly be attributed to sample size.

Next generation sequencing (NGS) methods have been applied to tumor tissue and revealed subtypes not known before the advent of these techniques [38]. Additionally, investigations on viral integration into the genome, detected by next generation sequencing, lead to insights into tumor pathogenesis [39]. Due to HPV vaccination a shift in prevalence of HPV types can be expected which makes testing for numerous HPV types important [40].
HPV was also detected in lymph node metastases. There are approaches to detect circulating cell free HPV DNA as a measure for disease control in oropharyngeal cancer [41]. This technique may eventually be applicable to penile carcinomas and could be used as a non-invasive test for the prediction of high risk for systemic disease.

In the setting of the LCD-Array test 32 HPV types can be detected, which exceeds the types tested by the aforementioned tests. Currently it is not feasible to apply NGS methods to the large amount of samples observed in daily routine, as the costs exceed the possible compensation. This is why LCD-Array technique is a fast and reliable alternative for routine practice.

\section{Conclusions}

p16 staining is in most cases sufficient for the detection of high risk HPV association of penile neoplasias. LCDArray is a feasible, sensitive and specific, as well as cost efficient diagnostic tool for HPV testing of FFPE tissue of penile cancer which can be applied in routine testing in addition to p16 staining or in clinical trials. LCDArray technique may serve as a helpful tool in the advent of other HPV subtypes emerging in the setting of HPV vaccinated patients. Readouts of molecular techniques must be interpreted with caution to not over interpret transient HPV infections in the setting of a positive HPV detection in non-neoplastic epithelium.

\section{Supplementary Information}

The online version contains supplementary material available at https://doi. org/10.1186/s12894-022-00962-4.

\begin{abstract}
Additional file 1: Fig. 1. Negative p16 stainings.
Additional file 2: Fig. 2. Positive p16 stainings.

Additional file 3: Fig. 3. A Kaplan-Meier-Estimator for p16 positive and negative staining for overall survival in the cohort of penile neoplasias ( $p=0.43$; Log-rank-test, Cox-Mantel and Peto-Pike). B Kaplan-MeierEstimator for LCD-Array with regard to HPV high risk positive and HPV high risk negative cases for overall survival in the cohort of penile neoplasias ( $p=0.59$; Log-rank-test, Cox-Mantel and Peto-Pike). C Kaplan-MeierEstimator for Sanger sequencing with regard to HPV high risk positive and HPV high risk negative cases for overall survival in the cohort of penile neoplasias ( $p=0.62$; Log-rank-test, Cox-Mantel and Peto-Pike).

Additional file 4: Table 1a. HPV status of invasive squamous cell carcinomas by 16 immunohistochemistry with regard to tumor characteristics in evaluable cases**. Table $\mathbf{1 b}$. HPV status by Sanger sequencing technique with regard to tumor characteristics in evaluable cases**.
\end{abstract}

\section{Acknowledgements \\ We thank Susanne Hansen and Elena Hartung for excellent technical assistance.}

\section{Authors' contributions}

RW wrote the manuscript and analyzed and interpreted the data. All other authors (KB, JVG, JC Jr., PJ, SV, MD) reviewed the manuscript and made substantial intellectual contributions to the study design, work and data 
acquisition and interpretation of data. MD additionally coordinated laboratory work, KB scanned slides. All authors approved the submitted version. All authors read and approved the final manuscript.

\section{Funding}

Open Access funding enabled and organized by Projekt DEAL. The study was financed by the Dr. Senckenberg Institute of Pathology, Frankfurt am Main. The institute approved the study and collection, analysis, and interpretation of data as well as writing the manuscript.

\section{Availability of data and materials}

The datasets used and/or analysed during the current study are available from the corresponding author on reasonable request.

\section{Declarations}

\section{Ethics approval and consent to participate}

Tissue samples and patient data used in this study were provided by the University Cancer Center Frankfurt (UCT). Written informed consent was obtained from all patients and the study was approved by the institutional review board of the UCT and the ethical committee at the University Hospital Frankfurt (project-number: SUG-02-2017) according to the declaration of Helsinki. For our studies, archived material was used in a double pseudonymised manner. Diagnostics were already finalised by the time of study.

\section{Consent for publication}

Not applicable.

\section{Competing interests}

PJW has received consulting fees and honoraria (private/institutional) for lectures by Bayer, Janssen-Cilag, Novartis, Roche, MSD, Astellas Pharma, BristolMyers Squibb, Thermo Fisher Scientific, Molecular Health, Sophia Genetics, Qiagen, and Astra Zeneca. All other authors have declared that no competing interests exists.

\section{Author details}

${ }^{1}$ Dr. Senckenberg Institute of Pathology, University of Frankfurt, Theodor-Stern-Kai 7, 60596 Frankfurt am Main, Germany. ${ }^{2}$ Department of Radiation Oncology, University of Frankfurt, Theodor-Stern-Kai 7, 60596 Frankfurt am Main, Germany. ${ }^{3}$ Institute of Medical Virology, University of Frankfurt, Theodor-Stern-Kai 7, 60596 Frankfurt am Main, Germany.

Received: 27 April 2021 Accepted: 24 January 2022

Published online: 29 January 2022

\section{References}

1. Brianti P, De Flammineis E, Mercuri SR. Review of HPV-related diseases and cancers. New Microbiol. 2017;40(2):80-5.

2. Hakenberg OW, Compérat E, Minhas S, Necchi A, Protzel C, Watkin N. Guidelines on penile cancer. 2014. https://uroweb.org/wp-content/uploa ds/12-Penile-Cancer_LR.pdf.

3. Moch H, Humphrey PA, Ulbright TM, Reuter VE, International Agency for Research on Cancer. WHO classification of tumours of the urinary system and male genital organs. http://publications.iarc.fr/Book-And-ReportSeries/Who-larc-Classification-Of-Tumours/Who-Classification-Of-Tumou rs-Of-The-Urinary-System-And-Male-Genital-Organs-2016.

4. Alemany L, Saunier M, Alvarado-Cabrero I, Quirós B, Salmeron J, Shin H-R, Pirog EC, Guimerà N, Hernandez-Suarez G, Felix A, Clavero O, Lloveras B, Kasamatsu E, et al. Human papillomavirus DNA prevalence and type distribution in anal carcinomas worldwide. Int J Cancer. 2015;136:98-107. https://doi.org/10.1002/ijc.28963.

5. Rubin MA, Kleter B, Zhou M, Ayala G, Cubilla AL, Quint WG, Pirog EC. Detection and typing of human papillomavirus DNA in penile carcinoma: evidence for multiple independent pathways of penile carcinogenesis. Am J Pathol. 2001;159:1211-8. https://doi.org/10.1016/S0002-9440(10) 62506-0.

6. S3-Leitlinie Diagnostik, Therapie und Nachsorge des Peniskarzinoms.
7. Rödel F, Martin D, Balermpas P, Wieland U, Winkelmann R, Riekmann T, Falk S, Rödel C, Fokas E. Modulation of radiation sensitivity and antitumor immunity by viral pathogenic factors: Implications for radio-immunotherapy. Biochim Biophys Acta (BBA) Rev Cancer. 2019;1871:126-37.

8. Azizi M, Tang DH, Verduzco D, Peyton CC, Chipollini J, Yuan Z, Schaible BJ, Zhou J-M, Johnstone PA, Giuliano A, Dhillon J, Spiess PE. Impact of PI3K-AKT-mTOR signaling pathway up-regulation on prognosis of penile squamous-cell carcinoma: results from a tissue microarray study and review of the literature. Clin Genitourin Cancer. 2019;17:e80-91. https:// doi.org/10.1016/J.CLGC.2018.09.012.

9. Union for International Cancer Control, Wittekind C, Wiley-VCH. TNM Klassifikation maligner Tumoren. https://www.wiley.com/en-us/TNM\% $3 \mathrm{~A}+$ Klassifikation+maligner+Tumoren\%2C+8+Auflage-p-9783527807 598.

10. Remmerbach TW, Brinckmann UG, Hemprich A, Chekol M, Kühndel K, Liebert UG. PCR detection of human papillomavirus of the mucosa: comparison between MY09/11 and GP5+/6+ primer sets. J Clin Virol. 2004;30:302-8. https://doi.org/10.1016/j.jcv.2003.12.011.

11. Altschul SF, Madden TL, Schäffer AA, Zhang J, Zhang Z, Miller W, Lipman DJ. Gapped BLAST and PSI-BLAST: a new generation of protein database search programs. Nucleic Acids Res. 1997;25:3389-402.

12. Ackermann H. BiAS. für Windows Version 11.10. Hochheim Darmstadt: Epsilon Verlag; 2020. https://ddei3-0-ctp.trendmicro.com:443/wis/click time/v1/query?url=www.bias-online.de\&umid=14D5D980-9C05-2305B9A0-BB88A7A07540\&auth=0add78fbf5bb9f3932276e031687124c15a 6990b-7248938d7cb0c02258e9a09f6afac64057baf54c.

13. Hulsen T, de Vlieg J, Alkema W. BioVenn-a web application for the comparison and visualization of biological lists using area-proportional Venn diagrams. BMC Genomics. 2008;9:488. https://doi.org/10.1186/ 1471-2164-9-488

14. Prigge E-S, Arbyn M, von Knebel Doeberitz M, Reuschenbach M. Diagnostic accuracy of p16 ${ }^{\text {INK4a }}$ immunohistochemistry in oropharyngeal squamous cell carcinomas: a systematic review and meta-analysis. Int J Cancer. 2017;140:1186-98. https://doi.org/10.1002/ijc.30516.

15. Alemany L, Cubilla A, Halec G, Kasamatsu E, Quirós B, Masferrer E, Tous S, Lloveras B, Hernández-Suarez G, Lonsdale R, Tinoco L, Alejo M, AlvaradoCabrero l, et al. Role of human Papillomavirus in penile carcinomas worldwide. Eur Urol. 2016;69:953-61. https://doi.org/10.1016/j.eururo. 2015.12.007.

16. Cullen M, Boland JF, Schiffman M, Zhang X, Wentzensen N, Yang Q, Chen Z, Yu K, Mitchell J, Roberson D, Bass S, Burdette L, Machado M, et al. Deep sequencing of HPV16 genomes: A new high-throughput tool for exploring the carcinogenicity and natural history of HPV16 infection. Papillomavirus Res. 2015;1:3-11. https://doi.org/10.1016/j.pvr.2015.05.004.

17. Tsiatis AC, Norris-Kirby A, Rich RG, Hafez MJ, Gocke CD, Eshleman JR, Murphy KM. Comparison of Sanger sequencing, pyrosequencing, and melting curve analysis for the detection of KRAS mutations: diagnostic and clinical implications. J Mol Diagn. 2010;12:425-32. https://doi.org/10. 2353/jmoldx.2010.090188.

18. Gao G, Wang J, Kasperbauer JL, Tombers NM, Teng F, Gou H, Zhao Y, Bao Z, Smith DI. Whole genome sequencing reveals complexity in both HPV sequences present and HPV integrations in HPV-positive oropharyngeal squamous cell carcinomas. BMC Cancer. 2019;19:352. https://doi.org/10. 1186/s12885-019-5536-1.

19. Lee SJ, Kim WY, Shim S-H, Cho S-H, Oh IK, Hwang TS, Kim S-N, Kang S-B. Semi-quantitative HPV viral load in patients with ASC-US cytology: viral load correlates strongly with the presence of CIN but only weakly with its severity. Cytopathology. 2015;26:19-25. https://doi.org/10.1111/cyt. 12146.

20. Mathieson W, Thomas G. Using FFPE tissue in genomic analyses: advantages, disadvantages and the role of biospecimen science. Curr Pathobiol Rep. 2019;7:35-40. https://doi.org/10.1007/s40139-019-00194-6.

21. Nucleic Acid Based Tests | FDA. https://www.fda.gov/medical-devices/ vitro-diagnostics/nucleic-acid-based-tests\#top.

22. digene HC2 high-risk HPV DNA test-QIAGEN online shop. https://www. qiagen.com/de/products/diagnostics-and-clinical-research/sexual-repro ductive-health/cervical-cancer-screening/digene-hc2-high-risk-hpv-dnatest-ce/\#orderinginformation.

23. Cuzick J, Cadman L, Mesher D, Austin J, Ashdown-Barr L, Ho L, Terry G, Liddle S, Wright C, Lyons D, Szarewski A. Comparing the performance of 
six human papillomavirus tests in a screening population. Br J Cancer. 2013;108:908-13. https://doi.org/10.1038/bjc.2013.22.

24. Eklund C, Forslund O, Wallin K-L, Dillner J. Global improvement in genotyping of human Papillomavirus DNA: the 2011 HPV LabNet International Proficiency Study downloaded from. J Clin Microbiol. 2014;52:2020.

25. Reich O, Regauer S, Kashofer K. Possibly carcinogenic HPV subtypes are a cause of HSIL and negative clinical HPV tests - a European prospective single center study. Gynecol Oncol. 2020. https://doi.org/10.1016/j.ygyno. 2020.04.685.

26. Nilyanimit P, Chansaenroj J, Poomipak W, Praianantathavorn K, Payungporn S, Poovorawan Y. Comparison of four human Papillomavirus genotyping methods: next-generation sequencing, INNO-LiPA, electrochemical DNA chip, and nested-PCR. Ann Lab Med. 2018;38:139. https://doi. org/10.3343/ALM.2018.38.2.139.

27. Castro FA, Koshiol J, Quint W, Wheeler CM, Gillison ML, Vaughan LM, Kleter B, van Doorn L-J, Chaturvedi AK, Hildesheim A, Schiffman M, Wang SS, Zuna RE, et al. Detection of HPV DNA in paraffin-embedded cervical samples: a comparison of four genotyping methods. BMC Infect Dis. 2015;15:1-11. https://doi.org/10.1186/S12879-015-1281-5.

28. Torii Y, Fujii T, Kukimoto I, Saito M, I wata T, Takahashi H, Ichikawa R, Kawai S, Otani S, Aoki D. Comparison of methods using paraffin-embedded tissues and exfoliated cervical cells to evaluate human papillomavirus genotype attribution. Cancer Sci. 2016;107:1520-6. https://doi.org/10 1111/CAS.13030.

29. Canete-Portillo S, Sanchez DF, Cubilla AL. Pathology of invasive and intraepithelial penile neoplasia. Eur Urol Focus. 2019;5:713-7. https://doi. org/10.1016/j.euf.2019.06.013.

30. Paolini F, Carbone A, Benevolo M, Silipo V, Rollo F, Covello R, Piemonte P, Frascione P, Capizzi R, Catricalà C, Venuti A. Human Papillomaviruses, p16 INK4a and Akt expression in basal cell carcinoma. J Exp Clin Cancer Res. 2011:30:1-9. https://doi.org/10.1186/1756-9966-30-108.

31. Zakrzewska K, Regalbuto E, Pierucci F, Arvia R, Mazzoli S, Gori A, de Giorgi V. Pattern of HPV infection in basal cell carcinoma and in perilesional skin biopsies from immunocompetent patients. Virol J. 2012;9:309. https://doi. org/10.1186/1743-422X-9-309.

32. Zhang G, Zhao Y, Abdul-Karim FW, Yang B. P16 expression in primary vulvar extramammary paget disease. Int J Gynecol Pathol. 2020;39:105-10. https://doi.org/10.1097/PGP.00000000000000602.

33. Sudenga SL, Ingles DJ, Pierce Campbell CM, Lin HY, Fulp WJ, Messina JL, Stoler MH, Abrahamsen M, Villa LL, Lazcano-Ponce E, Giuliano AR. Genital human Papillomavirus infection progression to external genital lesions: the HIM study. Eur Urol. 2016;69:166-73. https://doi.org/10.1016/j.eururo. 2015.05.032.

34. Gheit T. Mucosal and cutaneous human Papillomavirus infections and cancer biology. Front Oncol. 2019;9:355. https://doi.org/10.3389/fonc. 2019.00355.

35. Iorga L, Marcu R, Diaconu C, Stanescu A, Stoian A, Mischianu D, Surcel M, Bungau S, Constantin T, Boda D, Fekete L, Bratu O. Penile carcinoma and HPV infection (review). Exp Ther Med. 2019;20:91-6. https://doi.org/10. 3892/etm.2019.8181.

36. Olesen TB, Sand FL, Rasmussen CL, Albieri V, Toft BG, Norrild B, Munk C, Kjær SK. Prevalence of human papillomavirus DNA and p16 INK4a in penile cancer and penile intraepithelial neoplasia: a systematic review and meta-analysis. Lancet Oncol. 2019;20:145-58. https://doi.org/10. 1016/S1470-2045(18)30682-X.

37. Badoual C, Hans S, Merillon N, Van Ryswick C, Ravel P, Benhamouda N, Levionnois E, Nizard M, Si-Mohamed A, Besnier N, Gey A, Rotem-Yehudar $\mathrm{R}$, Pere $\mathrm{H}$, et al. PD-1-expressing tumor-infiltrating $\mathrm{T}$ cells are a favorable prognostic biomarker in HPV-associated head and neck cancer. Cancer Res. 2013;73:128-38. https://doi.org/10.1158/0008-5472.CAN-12-2606.

38. Bzhalava D, Mühr LSA, Lagheden C, Ekström J, Forslund O, Dillner J, Hultin E. Deep sequencing extends the diversity of human papillomaviruses in human skin. Sci Rep. 2014;4:1-7. https://doi.org/10.1038/srep05807.

39. Groves IJ, Coleman N. Human papillomavirus genome integration in squamous carcinogenesis: what have next-generation sequencing studies taught us? J Pathol. 2018:245:9-18. https://doi.org/10.1002/path.5058.

40. Fischer S, Bettstetter M, Becher A, Lessel M, Bank C, Krams M, Becker I, Hartmann A, Jagla W, Gaumann A. Shift in prevalence of HPV types in cervical cytology specimens in the era of HPV vaccination. Oncol Lett. 2016;12:601-10. https://doi.org/10.3892/ol.2016.4668.
41. Economopoulou P, Koutsodontis G, Avgeris M, Strati A, Kroupis C, Pateras I, Kirodimos E, Giotakis E, Kotsantis I, Maragoudakis P, Gorgoulis V, Scorilas A, Lianidou E, et al. HPV16 E6/E7 expression in circulating tumor cells in oropharyngeal squamous cell cancers: a pilot study. PLoS ONE. 2019;14:e0215984. https://doi.org/10.1371/journal.pone.0215984.

\section{Publisher's Note}

Springer Nature remains neutral with regard to jurisdictional claims in published maps and institutional affiliations.

Ready to submit your research? Choose BMC and benefit from:

- fast, convenient online submission

- thorough peer review by experienced researchers in your field

- rapid publication on acceptance

- support for research data, including large and complex data types

- gold Open Access which fosters wider collaboration and increased citations

- maximum visibility for your research: over $100 \mathrm{M}$ website views per year

At BMC, research is always in progress.

Learn more biomedcentral.com/submissions 